\title{
Lacrimal Sac Mucoepidermoid Carcinoma with Metastases to the Cavernous Sinus Following Dacryocystorhinostomy Treated with Stereotactic Radiotherapy
}

\author{
Jonathan C.P. Roos Bijan Beigi
}

Adnexal Service, Department of Ophthalmology, Norfolk and Norwich University Hospital NHS Foundation Trust, Norwich, United Kingdom

\section{Keywords}

Mucoepidermoid carcinoma · External dacryocystorhinostomy · Gamma Knife · Cavernous sinus - Osteotomy

\section{Abstract}

Purpose: We report a very good outcome in a 44-year-old woman in whom cancer was missed as the cause of nasolacrimal duct obstruction and dacryocystitis and which was deemed inoperable after spreading to the cavernous sinus. Case Report: The patient was referred to our unit 12 months following uneventful right dacryocystorhinostomy for nasolacrimal duct obstruction. This had been complicated by the formation of a significant canthal swelling 6 months later, which had been excised at that time. The symptom of nasolacrimal duct obstruction and scar recurrence prompted the referral to our unit. Examination and biopsy confirmed a malignancy. Despite extensive surgery, including concurrent radical neck dissection and parotidectomy, within 6 months, her mucoepidermoid carcinoma was found to have spread to the cavernous sinus, restricting blood flow from the carotid and causing an abducens nerve palsy. Though deemed inoperable at first, Gamma Knife stereotactic radiosurgery was sought as treatment for her disease, resulting in a good outcome 4 years after surgery. Conclusion: Experience from this case suggests the importance of considering malignancy as a cause in young patients when presenting with nasolacrimal duct 
Case Reports in
Ophthalmology

Case Rep Ophthalmol 2016;7:274-278

$10.1159 / 000446152$

www.karger.com/cop

Roos and Beigi: Lacrimal Sac Mucoepidermoid Carcinoma with Metastases to the Cavernous Sinus after Dacryocystorhinostomy Treated with Stereotactic Radiotherapy

obstruction. In such cases, and perhaps for all patients, biopsy specimens should be submitted as many tumours are found incidentally at the time of dacryocystorhinostomy. Whilst the external approach to dacryocystorhinostomy may identify abnormal anatomy intraoperatively, prompting biopsy, this is less likely with an endonasal approach where osteotomy precedes sac visualisation. The endonasal approach may therefore be less appropriate in such cases where malignancy is suspected as osteotomy may aid in the spread.

(C) 2016 The Author(s)

Published by S. Karger AG, Basel

\section{Introduction}

Lacrimal sac tumours can be malignant and life-threatening. But as they are rare, the diagnosis may be overlooked, especially in the young. We report a case of recurrent dacryocystitis referred to us for revision of dacryocystorhinostomy in whom a carcinoma was confirmed with subsequent metastases to the cavernous sinus.

\section{Case Report}

A 44-year-old woman presented to another centre complaining of right epiphora for the past 12 months. There was no history of dacryocystitis or fluctuating symptoms. Nasolacrimal duct obstruction was diagnosed and an uneventful dacryocystorhinostomy performed. Six months later, a hypertrophic scar at the dacryocystorhinostomy incision site had formed and was excised. However, no tissue was sent for histological examination. When, after a further 6 months, the hypertrophic swelling around the medial canthal tendon had reformed and a further intervention was being planned, a second opinion was sought and she was referred to our unit. She was now again symptomatic with epiphora and mucous discharge. A right medial canthal lump extending above the tendon was noted with the absence of cellulitis (fig. 1). Magnetic resonance imaging (MRI) of the orbit and paranasal sinuses showed an area of marked scarring in the site of the previous osteotomy (fig. 2).

She underwent an exploratory external dacryocystorhinostomy with excision of an excessive amount of scar tissue in the area of the lacrimal sac. The canaliculus was re-canalised to the nasal cavity through the previous osteotomy. Histology demonstrated a high-grade mucoepidermoid carcinoma close to the surgical margin. Subsequent MRI showed probable metastasis to the cervical lymph nodes without orbit, paranasal or cavernous sinus involvement. A localised extensive excision of the lacrimal sac, nasolacrimal duct, paranasal sinuses, and the adjacent skin and a radical neck dissection were performed including parotidectomy. She had an uneventful postoperative recovery.

However, she presented with a horizontal diplopia 6 months later due to right abducens and trochlear cranial nerve palsies. Repeat magnetic resonance neuroimaging demonstrated a gadolinium-enhancing infiltrate in the right cavernous sinus surrounding and compressing the carotid artery (fig. 3). Neurosurgical review suggested that this was an inoperable location. We therefore sought fractionated stereotactic radiotherapy (Gamma Knife) to the cavernous sinus at a national centre to provide high-dose radiation for local control of the disease. This was delivered by 55 Gy over 33 sessions. Fortunately, MRI scan 6 months later showed a significant reduction of cavernous sinus infiltrate. After almost 4 years, she is fit and well and - to our surprise - her most recent MRI shows complete resolution of the tu- 


\section{Case Reports in Ophthalmology}

mour on a macroscopic level. However, she remains under observation and her overall prognosis must still be considered guarded.

\section{Discussion}

Lacrimal sac tumours are fortunately not common, accounting for only around $1.4 \%$ of duct obstructions requiring dacryocystorhinostomy [1]. However, among these, 50\% are malignant [2] with the peak incidence at around 50 years of age, although younger age groups can also be affected $[3,4]$. A variety of cell types have been reported including squamous cell carcinoma and mucoepidermoid carcinoma [5] as in this case.

Identifying patients with lacrimal sac tumours can be difficult. Not all present with a medial canthal lump and many investigations for diagnosis of epiphora can fail to identify such pathology. A study by Anderson et al. [6] found that in a series of 377 routine biopsies performed during dacryocystorhinostomy, neoplasia was identified unexpectedly in $2.1 \%$.

However, attention to history and examination can help identify those patients requiring further investigations for secondary causes of nasolacrimal duct obstruction. For example, a prior history of cancer, male gender [1], age younger than 50 or bilateral disease [4] suggest the need to consider the possibility of a secondary cause. Pain, epistaxis or a history of blood arising from the punctum are not usually suggestive of a neoplastic cause [7]. On examination, neoplastic swellings are usually not inflamed (unlike in dacryocystitis) but will feel firm and non-fluctuant and may have associated telangiectasia and skin ulceration [7]. Should the lump extend above the medial canthal tendon, this is highly suggestive of tumour [8].

Intra-operatively, the presence of tumour may be suggested by a thickened lacrimal sac wall or absence of lumen, and this should prompt urgent biopsy. The results should be awaited prior to performing osteotomy with the surgery abandoned until a diagnosis is confirmed, for osteotomy may promote retrograde spread. This may be a potential drawback of the endonasal dacryocystorhinostomy approach where osteotomy precedes sac visualisation.

Histological confirmation of disease is frequently omitted for routine dacryocystorhinostomy operations performed in the UK, and perhaps increasingly so with the growing popularity of the endonasal dacryocystorhinostomy approach. There is widespread disparity in practice, with only some clinicians routinely sending off all tissue for microscopic review. We suggest such an approach would provide added assurance as $2.1 \%$ of cancers are detected incidentally on routine biopsy during dacryocystorhinostomy [6].

If tumour is confirmed histologically, an extensive excision of the lacrimal sac and soft tissue around it with radical neck dissection, with adjuvant post-operative radiotherapy as necessary, is the main line of treatment. Our patient benefitted from Gamma Knife surgery a technique invented at the Karolinska Institutet in Stockholm in 1967. It uses high-intensity cobalt radiation focussed over a small volume to achieve tumour clearance [9]. Gamma Knife has been used successfully for metastases to the cavernous sinus before [10], but as we now approach 4 years since treatment, this patient has amongst the longest disease-free intervals we have found in the literature for a cavernous sinus metastasis treated with stereotactic radiotherapy. 
Case Reports in
Ophthalmology

Case Rep Ophthalmol 2016;7:274-278 $10.1159 / 000446152$ www.karger.com/cop

Roos and Beigi: Lacrimal Sac Mucoepidermoid Carcinoma with Metastases to the Cavernous Sinus after Dacryocystorhinostomy Treated with Stereotactic Radiotherapy

\section{Acknowledgement}

The authors wish to thank the patient for permission to publish these images.

\section{Statement of Ethics}

The authors have no ethical conflicts to disclose.

\section{Disclosure Statement}

The authors have no conflicts of interest to report.

\section{References}

1 Bewes T, Sacks R, Sacks PL, Chin D, Mrad N, Wilcsek G, Tumuluri K, Harvey R: Incidence of neoplasia in patients with unilateral epiphora. J Laryngol Otol 2015;129(suppl 3):S53-S57.

2 Montalban A, Liétin B, Louvrier C, Russier M, Kemeny JL, Mom T, Gilain L: Malignant lacrimal sac tumors. Eur Ann Otorhinolaryngol Head Neck Dis 2010;127:165-172.

3 Ni C, D'Amico DJ, Fan CQ, Kuo PK: Tumors of the lacrimal sac: a clinicopathological analysis of 82 cases. Int Ophthalmol Clin 1982;22:121-140.

4 Sobel RK, Carter KD, Allen RC: Bilateral lacrimal drainage obstruction and its association with secondary causes. Ophthal Plast Reconstr Surg 2014;30:152-156.

-5 Stefanyszyn MA, Hidayat AA, Pe'er JJ, Flanagan JC: Lacrimal sac tumors. Ophthal Plast Reconstr Surg 1994;10:169-184.

6 Anderson NG, Wojno TH, Grossniklaus HE: Clinicopathologic findings from lacrimal sac biopsy specimens obtained during dacryocystorhinostomy. Ophthal Plast Reconstr Surg 2003;19:173-176 Parmar DN, Rose GE: Management of lacrimal sac tumours. Eye 2003;17:599-606.

8 Ryan SJ, Font RL: Primary epithelial neoplasms of the lacrimal sac. Am J Ophthalmol 1973;76:73-88.

-9 Coffey RJ, Flickinger JC, Lunsford LD, Bissonette DJ: Solitary brain metastasis: radiosurgery in lieu of microsurgery in 32 patients. Acta Neurochir Suppl (Wien) 1991;52:90-92.

10 Tsuda H, Ishikawa H, Asayama K, Saito T, Endo S, Mizutani T: Abducens nerve palsy and Horner syndrome due to metastatic tumor in the cavernous sinus. Intern Med 2005;44:644-646.

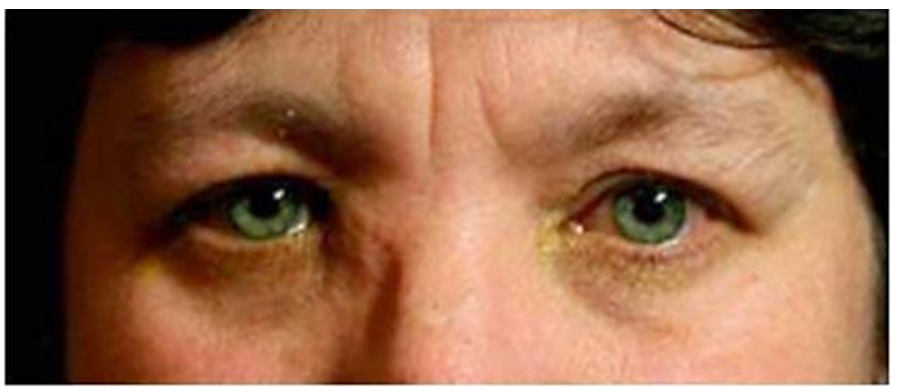

Fig. 1. Patient at presentation following recurrence of epiphora 1 year after right external dacryocystorhinostomy. 


\section{Case Reports in Ophthalmology}

\begin{tabular}{l|l}
\hline Case Rep Ophthalmol 2016;7:274-278 \\
\hline $10.1159 / 000446152$ & $\begin{array}{l}\text { ○ 2016 The Author(s). Published by S. Karger AG, Basel } \\
\text { www.karger.com/cop }\end{array}$ \\
\hline
\end{tabular}

Roos and Beigi: Lacrimal Sac Mucoepidermoid Carcinoma with Metastases to the Cavernous Sinus after Dacryocystorhinostomy Treated with Stereotactic Radiotherapy
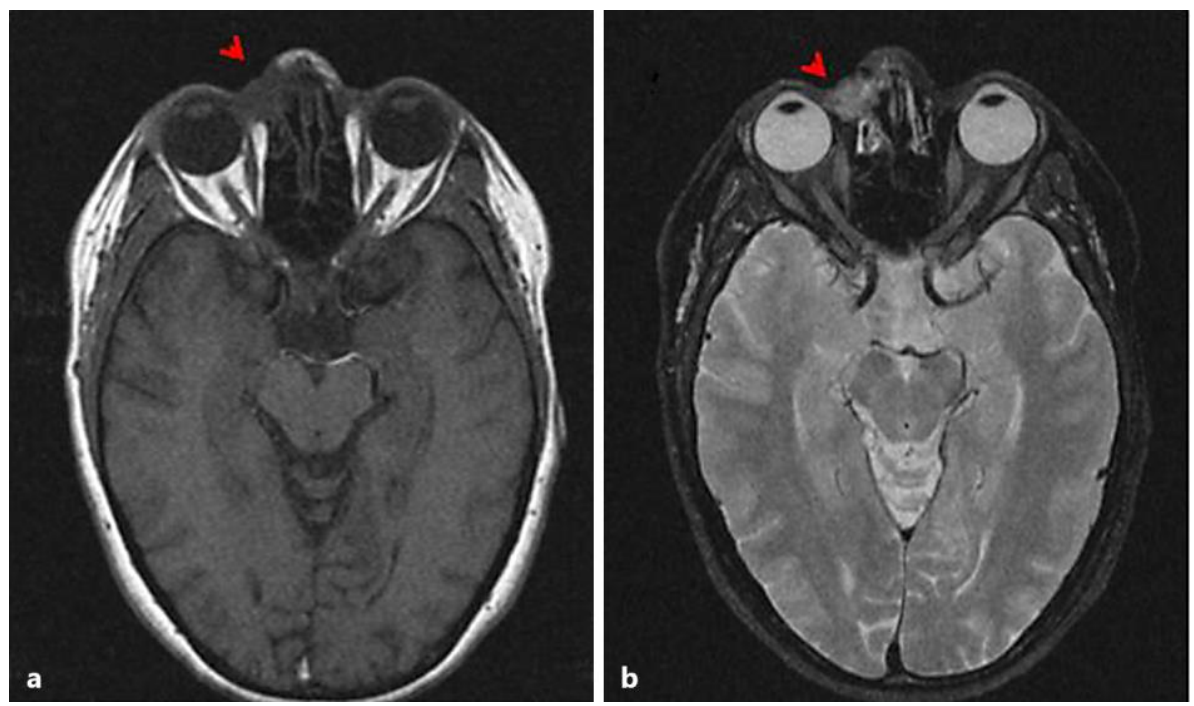

Fig. 2. MRI with T1 (a) and T2 (b) weighting showing the presence of lacrimal sac mass at the time of presentation. The cavernous sinus is disease free.
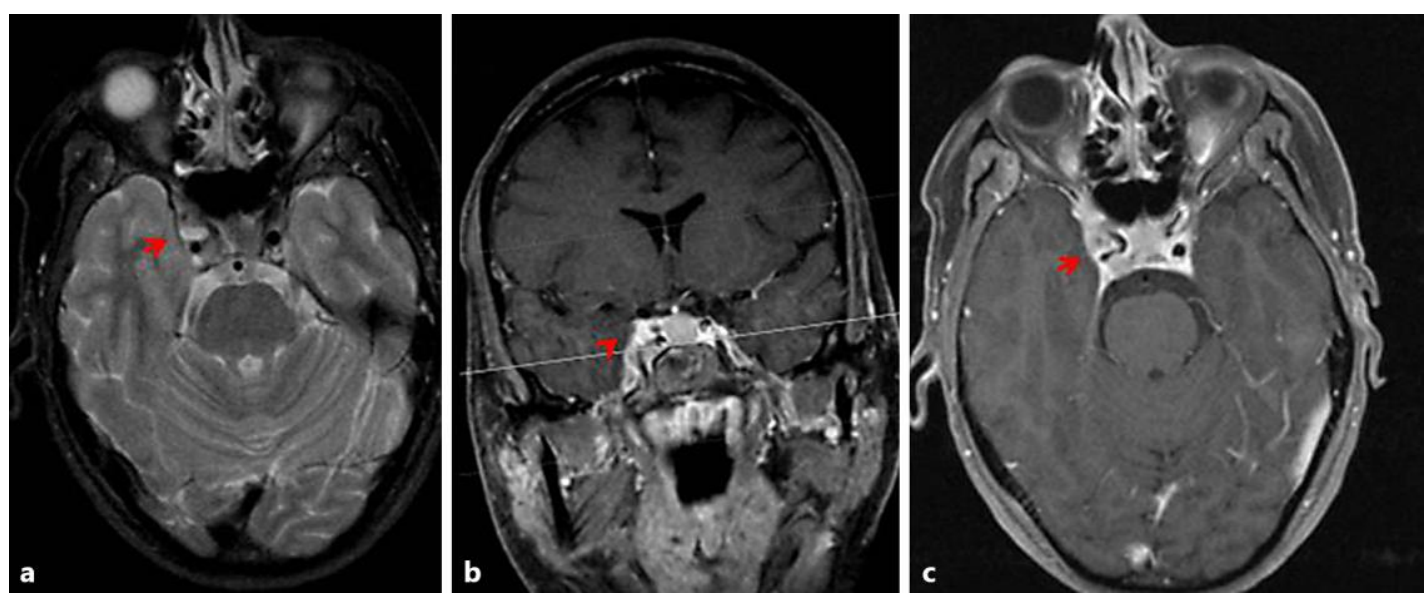

Fig. 3. T2-weighted MRI (a, b) showing the presence of a mass surrounding the internal carotid artery in the cavernous sinus 6 months following extensive cancer-clearing surgery. The lesion is marked with arrow heads and enhanced with contrast and T1 imaging (c). 